\title{
CONTRIBUIÇÕES À IMPLANTAÇÃO DE POLO MOVELEIRO NA REGIÃO CENTRAL DO TOCANTINS
}

\author{
Jorge D’ Ambros ${ }^{1}$, Joaquim Carlos Gonçalez ${ }^{2}$, Humberto Angelo ${ }^{3}$
}

(recebido: 14 de junho de 2010; aceito: 28 de fevereiro de 2012)

\begin{abstract}
RESUMO: Trata-se de estudo desenvolvido na região central do Tocantins para ouvir atores locais, especialistas no segmento moveleiro, na identificação e análise de fatores positivos, deficiências, oportunidades e ameaças associadas à cadeia produtiva, visando a dar continuidade à formação do polo. Foram ouvidos setenta e cinco atores locais dentre empresários do setor, academia universitária e entidades representantes do governo que opinaram sobre as contribuições econômicas, sociais, políticas e ambientais advindas da constituição de um polo na região. A ferramenta utilizada foi a SWOT Analysis associada ao Método de Juízes, as variáveis foram submetidas à Análise em Componentes Principais - ACP. A Matriz SWOT mostrou-se adequada e eficaz para ser utilizada como ferramenta de diagnóstico junto aos atores locais. $\mathrm{O}$ exame do conjunto de fatores associados à produção moveleira local ajudou a compreender a atividade e indicar ações que influenciam esse arranjo produtivo e que trará benéficos econômicos, sociais e ambientais. Na opinião dos avaliadores, a implantação de um polo moveleiro na região favorecerá, especialmente, a geração de emprego e renda, o desenvolvimento local e regional sustentável, melhorias na gestão dos negócios elevando o padrão de qualidade e produtividade das indústrias moveleiras e a qualidade de vida da população.
\end{abstract}

Palavras-chave: Análise SWOT, gestão estratégica, desenvolvimento local.

\section{CONTRIBUTIONS TO THE DEPLOYMENT OF FURNITURE IN POLE CENTRAL REGION TOCANTINS}

\begin{abstract}
This study was developed in the central region of Tocantins, for the identification and analysis of positive factors, weaknesses, opportunities and threats associated with the furniture supply chain in order to continue the formation of the regional furniture pole. To achieve this objective the methodology used was to listen to local actors and experts in the furniture segment. Seventy-five local actors among industry officials, academic institutions and university representatives were interviewed. They pointed out and analyzed the main points related to the economic, social, political and environmental contributions stemming from the creation of a pole in the region. The tool used was the SWOT Analysis associated with the Method of Judges, and then the variables were subjected to Principal Component Analysis - PCA. The SWOT Matrix proved to be adequate and effective to be used as diagnostic tool along with local actors. The examination of all the factors associated with local furniture production chain helped to understand the activity and indicate actions that affect this arrangement and that will bring economic, social and environmental benefits. According to the experts, the establishment of a furniture industry in the region will favor the employment and income creation, local and regional sustainable development, improvements in business management, raise the standard of quality and productivity of the local furniture industry and improve the quality of population standard of living.
\end{abstract}

Key words: SWOT analysis, strategic management, local development.

\section{INTRODUÇÃO}

O setor moveleiro destaca-se em várias regiões brasileiras pela sua dinâmica adaptação à economia de mercado e participação no desenvolvimento econômico, social e político, melhoria da qualidade de vida das pessoas e crescente uso sustentável dos recursos naturais*.

\footnotetext{
${ }^{*}$ A sustentabilidade resultará da aquisição de matéria-prima certificada, tratamento dos resíduos, uso no processo produtivo de ferramentas como a produção mais limpa, "5 menos que são mais" e sistema de gestão ambiental 14000 dentre outros, desta forma evitando ou reduzindo o desperdício.
}

A organização em redes de empresas ou polos moveleiros é uma moderna estratégia de gestão e reorganização do processo produtivo e eficácia comprovada também em outros países, como Itália e Alemanha (SILVA, 2006). Uma das grandes vantagens dessa metodologia é tornar os atores locais protagonistas de seu próprio desenvolvimento e possibilitar ao empresário acesso à inovação, cooperação, novas aprendizagens, produção em escala, enfim, realizar projetos que individualmente teriam poucas chances de viabilizar. De uma forma mais prática, permite realizar compras coletivas de matéria-prima,

\footnotetext{
${ }^{1}$ Administrador, Professor Doutor em Ciências Florestais - Universidade Federal do Tocantins - Av. NS 15 ALC NO 14 - 77020-210 - Palmas, TO, Brasil - jorge@uft.edu.br

${ }^{2}$ Engenheiro Florestal, Professor Doutor em Ciências Florestais - Universidade de Brasília - Departamento de Engenharia Florestal - Cx. P. 04357 70919-970 - Brasília, DF, Brasil - goncalez@unb.br

${ }^{3}$ Engenheiro Florestal, Professor Doutor em Engenharia Florestal - Universidade de Brasília - Departamento de Engenharia Florestal - Cx. P. 04357 70919-970 - Brasília, DF, Brasil - humberto@unb.br
}

Cerne, Lavras, v. 18, n. 3, p. 377-386, jul./set. 2012 
capacitações conjuntas, intercâmbio de idéias e alternativas de solução para os problemas locais e específicos do setor.

Nesse sentido, os empresários e funcionários das movelarias tocantinenses, as localizadas na região central do Estado, participaram de vários eventos promovidos pela Universidade Federal do Tocantins (UFT) e pelo Serviço Brasileiro de Apoio a Micro e Pequena empresa (SEBRAE). Estes visaram, especialmente, a desenvolver e implantar os princípios da qualidade, associativismo, da gestão estratégica e da formação de núcleo de conhecimento para a estruturação de um polo moveleiro na região.

Com a finalidade de dar continuidade a essas ações, foi desenvolvida pesquisa junto aos empresários do setor, à universidade e as entidades representantes do governo, visando a identificar os pontos fortes, dificuldades, oportunidades e ameaças dos fatores econômicos, sociais, políticos e ambientais que devem ser considerados na formação de um polo moveleiro. Neste trabalho, objetivouse contribuir na identificação e análise de fatores positivos, deficiências, oportunidades e ameaças associadas à cadeia moveleira da região central do Estado do Tocantins que, na opinião dos especialistas entrevistados, interferem na formação de um polo moveleiro na região.

\section{MATERIAL E MÉTODOS}

\section{1 Área de estudo, amostra e coleta de dados}

A área de estudo está localizada na região central do Tocantins, formada pelas cidades de Palmas, Porto Nacional e Paraíso do Tocantins. Essa região apresenta como vantagens a localização geográfica próxima a Transbrasiliana (BR 153) e Ferrovia Norte Sul, distância máxima de $60 \mathrm{~km}$ entre si e, em especial, foi objeto de vários projetos e cursos organizados pela UFT ${ }^{*}$ financiados pela FINEP. Preliminarmente, foi realizado um levantamento na região para identificar os principais atores envolvidos na cadeia produtiva moveleira local. Parte desse grupo de atores locais ou especialistas, formados por professores universitários, representantes do Governo do Estado, empresários e sindicato da categoria, participaram na construção da matriz para a coleta de dados. A formatação do instrumento de pesquisa contou ainda com colaboração dos estudos realizados por Paula (2008) e Silva (2006), conhecimento do pesquisador sobre o tema.

\footnotetext{
*A atuação da UFT ocorreu especialmente através do Centro Tecnológico de Madeira e Móveis do Tocantins (CTMM), criado em 2005.
}

Essas sugestões deram origem a Matriz SWOT com quarenta (40) diferentes questões (variáveis), distribuídas em dez (10) para cada quadrante: pontos fortes, deficiências, oportunidades e ameaças. Para identificar e listar essas variáveis empregou-se o Método de Juízes** (MALHOTRA, 1993), mediante aplicação de entrevistas pelo pesquisador e por meio de envio da matriz por meio eletrônico, a 150 especialistas do setor moveleiro selecionados anteriormente.

\subsection{Análise dos dados}

A $S W O T^{* * *}$ Analysis, associada ao Método de Juízes, permitiu identificar e analisar fatores internos e externos, assim como estabelecer cruzamento entre as variáveis de cada quadrante. Posteriormente, as variáveis foram submetidas à análise fatorial (Análise por Componentes Principais - ACP), com a finalidade de reduzir o número e agrupá-las de forma que se perdesse o mínimo de informação. A análise SWOT é considerada uma metodologia de gestão, integra as metodologias de planejamento estratégico e auxilia na identificação e análise das variáveis internas e externas; estabelece prioridades estratégicas para ação, e conduz a uma relação adequada entre o mercado e as capacidades institucionais. Segundo Marcelino e Fuscaldi (2008), pode ser aplicada a uma nação, região, território ou empresa.

Outro aspecto que favorece sua disseminação nas instituições públicas e privadas é sua simplicidade na execução, flexibilidade, integração de informações qualitativas e quantitativas e grande estímulo à participação e colaboração dos atores envolvidos no processo, mesmo entre aqueles que têm pouco contato entre si (MONTEIRO et al., 2001).

A matriz SWOT, quando utilizada na leitura de cenários ou avaliação crítica das capacidades internas (nível/micro), identifica pontos fortes e deficiências, variáveis controláveis pela organização, que indicam uma posição atual da mesma ou projeto, enquanto que o ambiente externo (nível/macro) deve ser analisado em termos das oportunidades e ameaças, consideradas variáveis não controláveis, relacionadas ao mercado e antecipam o que poderá vir a ocorrer (OLIVEIRA, 2006).

\footnotetext{
**O Método de Juízes (MALHOTRA, 1993), refere-se a possibilidade metodológica de convidar especialista sobre determinado tema (Juízes) a opinarem sobre o tema em estudo.

***A sigla SWOT é um anacrônico formado pelas palavras inglesas: Strengths (forças), Weaknesses (fraquezas), Opportunities (oportunidades) e Threats (ameaças).
}

Cerne, Lavras, v. 18, n. 3, p. 377-386, jul./set. 2012 
No que diz respeito à apreciação crítica de resultados quando da aplicação da ferramenta, um aspecto relevante é a análise das correlações entre os quadrantes da matriz, permitindo visualizar as potencialidades e a capacidade de aproveitar as oportunidades mediantes seus atuais pontos fortes (isso é possível quando se cruzam os pontos fortes versus oportunidades); a capacidade defensiva da instituição de minimizar as ameaças pelo uso de seus pontos fortes pelo cruzamento desses versus ameaças; as debilidades da instituição que dificultam o aproveitamento das oportunidades quando são correlacionados os pontos fracos versus oportunidades e, finalmente, o cruzamento de pontos fracos versus ameaças, que oportunizam visualizar as vulnerabilidades da organização (SEIFRIET, 2009).

Análise em Componentes Principais (ACP) é uma técnica exploratória que permite realizar análise multidimensional eficiente para a variância dos dados. Normalmente, o pesquisador parte de um número elevado de variáveis observadas para obter um número reduzido de fatores que "resumem" essas variáveis ou atributos, com um mínimo de perda dessa informação (ANGELO; PRADO, 2008). Após essa análise, os novos conceitos poderão ser trabalhados e analisados como variáveis "normais". Os autovetores são formados por um conjunto de eixos (componentes ou fatores) extraídos de uma matriz de semelhança entre variáveis e autovalores que explicam o comprimento dos autovetores que representam sua importância (\%) para explicar a variância total dos dados, denominada de análise da comunalidade (ALMEIDA, 1995).

Para identificar as questões mais importantes realizou-se análise de frequência simples, colocando em evidência os itens com maior pontuação e sua relação com a nota total. Posteriormente, em razão da quantidade de variáveis consideradas, utilizou-se técnica de análise multivariada, analisando-se a dependência das variáveis em relação às outras. Considerando a precisão desejada, os objetivos a serem alcançados e a maior facilidade de análise optou-se pela análise (ACP).

\subsubsection{Teste de esferecidade de Bartlett}

Testa a possibilidade de rejeitar a hipótese nula (ausência de associação), indicando que as variáveis apresentam correlações significativas. Neste caso, a hipótese de nulidade: $\mathrm{H}_{0}: \mathrm{V}=\mathrm{A}$, onde "V" é a matriz de correlação variáveis e "A" é a matriz de avaliação dos especialistas. A estatística do teste de hipótese de ausência de associação é dada por:

$$
[n-1-1 / 2(2 v+5)] \operatorname{In}|R| \text {, sendo " } \mathrm{n} \text { " o número de }
$$
indivíduos e " $\mathrm{v}$ " o número de variáveis observadas: " $\mathrm{R}$ " é a matriz de correlações amostrais.

\subsubsection{Caracterização das componentes principais}

A técnica consiste em obter combinações lineares originais, em número menor que o inicial, ou redução do espaço paramétrico, com as propriedades da soma dos quadrados dos coeficientes resultantes na unidade e um novo conjunto de variáveis não correlacionadas entre si.

2.2.3 Determinação do número de componentes principais para representar adequadamente os dados iniciais

Para determinar o número de componentes principais foram utilizados dois critérios principais: Critério de Kaiser, valor próprio maior do que 1, (KAISER, 1958 citado por BOLOGNA, 2007) e Critério de Cattell, distribuição gráfica dos valores próprios, scree plot (GOUVEIA et al., 2008).

\subsubsection{Obtenção dos componentes principais}

O processamento dos dados foi feito por meio do programa computacional Statistical Package for the Social Sciences (SPSS) que estabeleceu correspondências entre os quarenta itens e os dez níveis de importância de cada um deles.

\section{RESULTADOS E DISCUSSÃO}

A Matriz SWOT permitiu identificar os pontos fortes e deficiências, oportunidades e ameaças da cadeia produtiva moveleira da região central do Tocantins, Tabela 1.

\subsection{Análise estratégica da matriz SWOT}

A partir das respostas dos especialistas entrevistados foram identificadas as principais questões referentes à gestão da cadeia produtiva moveleira para a região central do Tocantins. Na Tabela 2, apresentam-se as variáveis mais significativas, em cada quadrante e o total de pontos atribuídos pelos especialistas.

$\mathrm{Na}$ opinião dos entrevistados, o polo moveleiro tocantinense será a força propulsora (pontos fortes) para a: X5 (Geração de emprego e renda); X10 (Promoção do desenvolvimento local/regional; melhoria da gestão empresarial das empresas envolvidas) e X6 (Padrão mais elevado de qualidade, produtividade e competitividade dos produtos). A ocorrência desses pontos fortes

Cerne, Lavras, v. 18, n. 3, p. 377-386, jul./set. 2012 
Tabela 1 - Fatores que devem ser considerados na formação de um polo moveleiro submetidas à avaliação dos especialistas.

Table 1 - Factors considered in the formation of a furniture industry submitted to experts evaluation.

\begin{tabular}{|c|c|c|}
\hline Ambiente & $\begin{array}{c}\text { Pontos fortes } \\
\text { (strengths) }\end{array}$ & $\begin{array}{l}\text { Deficiências } \\
\text { (weaknesses) }\end{array}$ \\
\hline \multirow[t]{2}{*}{ Interno } & $\begin{array}{l}\text { 1. Acessar mercados mais seletivos } \\
\text { 2. Atualização tecnológica do setor } \\
\text { 3. Crescimento coletivo via inovação e Aprendizado } \\
\text { conjunto (coletivo) } \\
\text { 4. Formação de micro-redes de empresas moveleiras } \\
\text { 5. Gerar emprego e renda } \\
\text { 6. Melhoria na gestão empresarial das empresas } \\
\text { envolvidas } \\
\text { 7. Oferecer produto diferenciado com maior valor } \\
\text { agregado } \\
\text { 8. Padrão mais elevado de qualidade, produtividade } \\
\text { e competitividade dos produtos. } \\
\text { 9. Planejar de forma sustentável a atividade } \\
\text { moveleira na região } \\
\text { 10. Promover o desenvolvimento local/regional }\end{array}$ & $\begin{array}{l}\text { 1. Baixa integração e coordenação entre os diversos } \\
\text { elos que compõem a rede de interação e } \\
\text { cooperação que afetam os níveis de confiança, } \\
\text { integração e aprendizado } \\
\text { 2. Baixos investimentos em design e pesquisa de } \\
\text { mercado } \\
\text { 3. Carência de fornecedores especializados em partes } \\
\text { e componentes } \\
\text { 4. Insuficiente desenvolvimento tecnológico } \\
\text { 5. Elevada informalidade } \\
\text { 6. Imagem setorial negativa } \\
\text { 7. Incipiente normatização técnica aplicada à produção } \\
\text { provocando aumento índice de desperdício, falta } \\
\text { de padronização... } \\
\text { 8. Baixa escolaridade dos recursos humanos que } \\
\text { atuam no setor } \\
\text { 9. Produção por encomenda } \\
\text { 10. Falta de qualificação da mão-de-obra }\end{array}$ \\
\hline & $\begin{array}{l}\text { Oportunidades } \\
\text { (opportunities) }\end{array}$ & $\begin{array}{l}\text { Ameaças } \\
\text { (threats) }\end{array}$ \\
\hline
\end{tabular}

1. Aprimoramento da logística regional

2. Aproveitar e aprimorar as peculiaridades locais/ regionais

3. Aumento da renda e densidade populacional aumentando a demanda local e regional de mobiliário

4. Clima de confiança e parceria entre empresários do setor favorável à criação de um polo moveleiro

5. Disponibilidade de matéria-prima - madeira oriunda de reflorestamento a médio e longo prazo

Externo

6. Dotar os agentes de visão estratégica capaz de lidar com a complexidade, profundidade e velocidade das mudanças

7. Maior promoção e difusão de conhecimento e informações mediante intercâmbio de idéias resultando em maior efetividade na capacitação, adoção de novas tecnologias e assistência técnica entre outros.

8. Recursos financeiros disponíveis para o setor ou área

9. Superar obstáculos quanto ao porte - produção em escala/produção de móveis em série.

10. Valorização dos produtos do setor moveleiro.

1. Burocracia governamental para o setor

2. Distância dos fornecedores de matéria-prima

3. Falta de disposição política

4. Falta de incentivos fiscais para a área da indústria

5. Foco regional de desenvolvimento orientado para outro setor

6. Inexistência de "expertise" regional para implantar um polo moveleiro

7. Inexistência de modelo de desenvolvimento semelhante no Estado

8. Mercado atendido por empresas já consolidadas

9. Políticas governamentais instáveis para o setor

10. Distância dos grandes mercados consumidores

Cerne, Lavras, v. 18, n. 3, p. 377-386, jul./set. 2012 
Tabela 2 - Variáveis com maior pontuação na avaliação dos especialistas.

Table 2 - Variables with the highest score in the experts evaluation.

\begin{tabular}{|c|c|}
\hline Pontos fortes & Deficiências \\
\hline $\begin{array}{l}\text { (X5) Gerar emprego e renda ( } 672 \text { pontos); } \\
\text { (X10) Promover o desenvolvimento local/regional ( } 640 \text { pontos); } \\
\text { (X6) Melhoria na gestão empresarial das empresas envolvidas } \\
\text { (637 pontos) } \\
\text { (X8) Padrão mais elevado de qualidade, produtividade e } \\
\text { competitividade dos produtos ( } 637 \text { pontos) }\end{array}$ & $\begin{array}{l}\text { (X20) Falta de qualificação de mão-de-obra ( } 681 \text { pontos); } \\
\text { (X12) Baixos investimentos em desing e pesquisa de mercado } \\
\text { (617 pontos) } \\
\text { (X14) Insuficiente desenvolvimento tecnológico ( } 616 \text { pontos) } \\
\text { (X1) Baixa integração e coordenação ( } 613 \text { pontos). }\end{array}$ \\
\hline Oportunidades & Ameaças \\
\hline $\begin{array}{l}\text { (X27) Maior promoção e difusão de conhecimento e } \\
\text { informações mediante intercâmbio de idéias resultando em } \\
\text { maior efetividade na capacitação, adoção de novas tecnologias } \\
\text { e assistência técnica entre outros ( } 644 \text { pontos); } \\
\text { (X28) Recursos disponíveis para o setor ou área (639 pontos) } \\
\text { (X30) Valorização dos produtos do setor moveleiro (639 } \\
\text { pontos); } \\
\text { (X26) Dotar os agentes de visão estratégica capaz de lidar com } \\
\text { a complexidade, profundidade e velocidade das mudanças ( } 632 \\
\text { pontos) }\end{array}$ & $\begin{array}{l}\text { (X33) Falta de disposição política ( } 584 \text { pontos); } \\
\text { (X31) Burocracia governamental para o setor ( } 583 \text { pontos); } \\
\text { (X34) Falta de incentivos fiscais para a área da indústria ( } 596 \\
\text { pontos). }\end{array}$ \\
\hline
\end{tabular}

indica potencial e capacidade para aproveitamento das oportunidades: X27 (Aproveitamento de outras vantagens próprias da formação de redes de empresas, tais como, maior promoção e difusão de conhecimentos e informações mediante intercâmbio de idéias, resultando em uma maior efetividade na capacitação; X28 (Adoção de novas tecnologias e assistência técnica; recursos disponíveis para o setor ou área; valorização dos produtos do setor moveleiro. X26 (Dotar os agentes de visão estratégica, capaz de lidar com a complexidade, profundidade e velocidade das mudanças). $\mathrm{Na}$ análise, foi possível verificar que as notas atribuídas nesses quadrantes apresentaram médias superiores à média geral da matriz SWOT $(7,9)$ e a variável X5 (Gerar Emprego e Renda). Destacou-se com a moda e média mais elevada, pois trinta e sete especialistas (49,3\%) atribuíram nota dez.

A importância dessas variáveis é ratificada pelos estudos de Porter (1999), quando afirma que os países melhor sucedidos são aqueles que privilegiam o conhecimento e competem no mercado com produtos e serviços de baixo custo e elevada qualidade, produtividade e competitividade. Outra constatação do autor refere-se à busca de condições externas de competitividade, que tem levado empresas a se deslocarem espacialmente, e a implantarem novas formas organizacionais e produtivas e a desenvolver novos produtos e mercados. Para Barquero
(2002), "a introdução de inovações - são sempre resultado coletivo da cooperação tácita entre as empresas - leva ao aumento da produtividade e da competitividade das economias locais".

O cruzamento dos "pontos fortes" e "ameaças" ao polo moveleiro revelaram a capacidade defensiva dos atores em utilizar os primeiros para minimizar o efeito das ameaças. Nesse sentido, apoiados nas fortalezas identificadas pelos especialistas, devem ser minimizadas as consequências da X31 (Burocracia governamental para o setor), X33 (A falta de disposição política) e X34 (A falta de incentivos fiscais para a área da indústria). No quadrante das ameaças, foram encontradas as menores médias e modas da matriz SWOT. Em pesquisa realizada pelo Serviço Brasileiro de Apoio a Micro e Pequenas Empresas - SEBRAE (2006), 53\% dos empresários afirmaram que a questão financeira é a principal causa impeditiva do acesso a novas tecnologias (apenas 10\% utilizam linhas de crédito), seguida pela burocracia e falta de informação. Para Medina (2006), apenas 37\% dos empresários moveleiros conhecem as formas de obtenção de financiamento. Na região central do Estado, os empresários apontaram a falta de capital de giro (31\%) como um dos maiores problemas da categoria. Esse problema poderia ser amenizado pela adoção de políticas públicas de apoio ao pequeno industrial.

Cerne, Lavras, v. 18, n. 3, p. 377-386, jul./set. 2012 
No cruzamento das deficiências e oportunidades foram identificadas as debilidades que impedem ao polo moveleiro o aproveitamento das oportunidades. $\mathrm{Na}$ opinião dos entrevistados, as deficiências que devem ser erradicadas ou minimizadas são: X20 (Falta de qualificação de mão de obra); X14 (Insuficiência do desenvolvimento tecnológico); X12 (Baixos investimentos em design e pesquisa de mercado) e X11 (Baixa integração e coordenação entre os diversos elos que compõem integração e cooperação que afetam os níveis de confiança, integração e aprendizado). Essas debilidades deverão ser atacadas para serem resolvidas nos três municípios. Nesse quadrante, identificou-se a variável X20 com maior média $(9,0)$ e moda, quarenta e seis entrevistados atribuíram nota dez. Finalmente, o cruzamento das deficiências e ameaças resultou na visualização das vulnerabilidades do polo que acentuam a possibilidade de concretização das ameaças X31, X3 e X34. Para Barbosa et al. (2001), o perfil tecnológico do setor madeireiro na Amazônia Central, apresenta problemas, tais como: parque tecnológico defasado, mão de obra sem qualificação, empresas descapitalizadas e novos desafios sendo gerados ao setor produtivo pelo mercado e legislações ambientais.

\subsection{Análise Fatorial Componentes Principais (ACP)}

O resultado obtido para o teste de esferecidade de Bartlett apresentou um valor de 2.122,36, bastante superior à distribuição do qui-quadrado com 780 graus de liberdade para um nível de significância de 1\%. Portanto, a hipótese nula é rejeitada e, logo, as quarenta variáveis apresentam correlações significativas.

\subsubsection{Obtenção dos componentes principais}

O número de fatores a serem considerados para análise dos dados foi definido a partir dos componentes principais, utilizando-se o critério de autovalor que representa a parcela da variância total explicada por cada fator. Na coluna dois da Tabela 3, os valores próprios (autovalores) ordenam-se por tamanho e a proporção da variância total explicada por cada componente corresponde ao quociente entre cada valor próprio e a variância total. A variância explicada pela primeira componente foi $30,19 \%$. Considerando o Critério de Kaiser e Critério de Cattell, foram selecionados treze componentes (Tabela 3) para a análise, os quais explicam $80,99 \%$ da variância total. Nesse caso, houve redução do espaço paramétrico da quadragésima para a décima terceira dimensão.

Cerne, Lavras, v. 18, n. 3, p. 377-386, jul./set. 2012
Tabela 3 - Matriz dos autovalores iniciais para a extração dos fatores componentes.

Table 3 - Matrix of eigenvalues for the initial extraction of component factors.

\begin{tabular}{cccc}
\hline Componente & Autovalor & $\begin{array}{c}\text { Variância } \\
\text { explicada (\%) }\end{array}$ & $\begin{array}{c}\text { Variância } \\
\text { acumulada (\%) }\end{array}$ \\
\hline 1 & 12,079 & 30,198 & 30,198 \\
2 & 3,396 & 8,491 & 38,689 \\
3 & 2,673 & 6,683 & 45,371 \\
4 & 2,610 & 6,525 & 51,896 \\
5 & 1,864 & 4,660 & 56,555 \\
6 & 1,816 & 4,541 & 61,096 \\
7 & 1,529 & 3,821 & 64,917 \\
8 & 1,341 & 3,353 & 68,270 \\
9 & 1,325 & 3,311 & 71,581 \\
10 & 1,046 & 2,614 & 74,196 \\
11 & 0,934 & 2,335 & 76,530 \\
12 & 0,918 & 2,294 & 78,824 \\
13 & 0,868 & 2,171 & 80,996 \\
\hline
\end{tabular}

Encontram-se na Tabela 4 as cargas fatoriais das treze primeiras componentes, suas variâncias e comunalidades das variáveis. A comunalidade resulta da soma das cargas fatoriais ao quadrado de cada linha e indica o quanto da variância de cada variável foi explicada pelos fatores. As dez variáveis que apresentaram maior peso (comunalidade) na explicação dos treze fatores que influenciam a estruturação do polo moveleiro foram: a) pontos fortes - X3 (Crescimento coletivo via inovação e aprendizado conjunto - coletivo); X5 (Gerar emprego e renda); X6 (Melhoria na gestão empresarial das empresas envolvidas); X9 (Planejar de forma sustentável a atividade moveleira na região); b) deficiências X14 (Insuficiente desenvolvimento tecnológico); c) oportunidades - X27 (Maior promoção e difusão de conhecimento e informações mediante intercâmbio de ideias resultando em maior efetividade na capacitação, adoção de novas tecnologias e assistência técnica entre outros); e das ameaças - X32 (Distância dos fornecedores de matéria-prima), X34 (Falta de incentivos fiscais para a área da indústria), X37 (Inexistência de modelo de desenvolvimento semelhante no Estado); X38 (Mercado atendido por empresas já consolidadas). As 30 demais variáveis apresentaram comunalidades entre 69,4 e 85,1\%. 
Tabela 4 - Matriz de cargas fatoriais das variáveis avaliadas pelos especialistas sobre os fatores que devem ser considerados na formação de um polo moveleiro.

Table 4-Matrix of loading factors of the variables assessed by experts on the factors that should be considered in the establishment of a furniture industry.

\begin{tabular}{|c|c|c|c|c|c|c|c|c|c|c|c|c|c|c|}
\hline \multirow{2}{*}{$\mathrm{V}^{1}$} & \multicolumn{13}{|c|}{ Fator } & \multirow{2}{*}{$\mathrm{CO}^{2}$} \\
\hline & 1 & 2 & 3 & 4 & 5 & 6 & 7 & 8 & 9 & 10 & 11 & 12 & 13 & \\
\hline $\mathrm{X} 1$ & 0,649 & 0,206 & 0,366 & 0,050 & 0,000 & 0,149 & 0,345 & $-0,025$ & $-0,074$ & 0,103 & 0,066 & $-0,069$ & 0,179 & $\mathbf{0 , 8 0 0}$ \\
\hline $\mathrm{X} 2$ & 0,760 & 0,262 & 0,170 & $-0,019$ & $-0,009$ & 0,270 & 0,040 & 0,273 & 0,037 & 0,011 & $-0,06$ & 0,066 & 0,055 &, 838 \\
\hline X3 & 0,367 & 0,425 & 0,105 & $-0,007$ & 0,159 & 0,230 & $-0,241$ & 0,033 & 0,440 & 0,017 & 0,349 & 0,115 & 0,301 & $\mathbf{0 , 8 8 3}$ \\
\hline $\mathrm{X} 4$ & 0,437 & 0,220 & 0,177 & $-0,058$ & $-0,026$ & 0,192 & 0,047 & 0,584 & $-0,119$ & 0,049 & $-0,02$ & 0,028 & $-0,13$ & $\mathbf{0 , 8 1 4}$ \\
\hline X5 & 0,333 & 0,806 & 0,095 & 0,195 & 0,032 & $-0,109$ & $-0,066$ & $-0,056$ & 0,059 & 0,002 & 0,117 & 0,028 & $-0,13$ & $\mathbf{0 , 8 6 1}$ \\
\hline X6 & 0,655 & 0,111 & 0,192 & 0,220 & 0,095 & 0,091 & $-0,178$ & 0,209 & $-0,260$ & $-0,027$ & 0,056 & $-0,419$ & 0,011 & $\mathbf{0 , 8 6 6}$ \\
\hline X7 & 0,653 & 0,261 & 0,303 & 0,142 & $-0,020$ & 0,084 & 0,025 & 0,068 & 0,128 & 0,059 & 0,300 & $-0,060$ & $-0,05$ & $\mathbf{0 , 7 3 5}$ \\
\hline X8 & 0,676 & 0,377 & 0,041 & 0,110 & 0,080 & 0,144 & 0,363 & 0,169 & 0,037 & 0,175 & 0,005 & $-0,024$ & 0,050 & $\mathbf{0 , 8 3 5}$ \\
\hline X9 & 0,549 & 0,180 & 0,047 & 0,475 & 0,254 & 0,019 & $-0,254$ & 0,185 & $-0,163$ & 0,221 & 0,231 & $-0,103$ & $-0,04$ & $\mathbf{0 , 8 6 7}$ \\
\hline X10 & 0,298 & 0,758 & 0,030 & 0,267 & 0,051 & 0,021 & 0,234 & 0,047 & 0,048 & 0,131 & 0,091 & 0,078 & $-0,02$ & $\mathbf{0 , 8 2 9}$ \\
\hline X11 & 0,341 & 0,011 & 0,138 & 0,017 & 0,190 & $-0,162$ & 0,045 & 0,198 & $-0,038$ & 0,743 & 0,133 & 0,149 & 0,047 & $\mathbf{0 , 8 3 9}$ \\
\hline X12 & 0,136 & 0,184 & 0,764 & $-0,056$ & $-0,073$ & 0,067 & 0,190 & $-0,102$ & 0,158 & 0,132 & 0,140 & 0,235 & 0,014 & $\mathbf{0 , 8 1 3}$ \\
\hline X13 & $-0,121$ & 0,115 & 0,200 & 0,133 & $-0,036$ & $-0,108$ & 0,114 & 0,041 & $-0,032$ & 0,067 & 0,098 & 0,842 & 0,008 & $\mathbf{0 , 8 2 4}$ \\
\hline X14 & 0,131 & 0,130 & 0,566 & 0,236 & 0,065 & $-0,155$ & $-0,075$ & 0,277 & 0,331 & 0,060 & $-0,040$ & 0,101 & $-0,08$ & $\mathbf{0 , 8 5 3}$ \\
\hline X15 & 0,065 & 0,049 & 0,151 & 0,268 & -0 & 0,156 & 0,125 & 0,099 & 0 & $-0,098$ & 0,117 & -0 & 0,105 & $\mathbf{0 , 8 1 1}$ \\
\hline X16 & 0,198 & 0,017 & 0,193 & $-0,073$ & 0,254 & 0,664 & 0,121 & 0,093 & 0,371 & 0,217 & 0,062 & 0,029 & $-0,08$ & $\mathbf{0 , 8 0 6}$ \\
\hline X17 & 0,012 & $-0,031$ & 0,661 & 0,010 & 0,236 & 0,078 & 0,044 & 0,347 & $-0,112$ & 0,277 & $-0,090$ & 0,054 & 0,086 & 0,728 \\
\hline X18 & 0,252 & 0,015 & 0,211 & 0,187 & 0,124 & 0,017 & 0,047 & 0,771 & 0,170 & 0,124 & 0,106 & 0,003 & $-0,140$ & $\mathbf{0 , 8 2 9}$ \\
\hline X19 & 0,134 & $-0,030$ & $-0,082$ & $-0,128$ & 0,006 & 0,736 & 0,130 & 0,137 & 0,120 & $-0,179$ & $-0,210$ & $-0,111$ & 0,180 & 0,752 \\
\hline X20 & 0,495 & 0,109 & $-0,107$ & $-0,031$ & $-0,275$ & 0,357 & 0,352 & 0,381 & 0,046 & $-0,113$ & 0,192 & 0,082 & 0,109 & $\mathbf{0 , 8 1 2}$ \\
\hline X21 & 0,020 & 0,531 & 0,417 & 0,088 & $-0,203$ & 0,035 & 0,267 & 0,061 & $-0,048$ & $-0,108$ & 0,221 & $-0,014$ & 0,224 & $\mathbf{0 , 6 9 4}$ \\
\hline X22 & 0,344 & 0,600 & 0,184 & $-0,012$ & 0,093 & $-0,039$ & 0,089 & 0,278 & 0,090 & $-0,450$ & $-0,060$ & 0,129 & 0,031 & $\mathbf{0 , 8 4 1}$ \\
\hline $\mathrm{X} 23$ & 0,607 & 0,342 & 0,325 & 0,149 & 0,129 & $-0,272$ & 0,094 & $-0,050$ & 0,097 & $-0,264$ & $-0,010$ & $-0,099$ & $-0,07$ & 0,81 \\
\hline X24 & 0,617 & 0,118 & 0,463 & 0,131 & 0,299 & $-0,102$ & $-0,040$ & $-0,122$ & 0,061 & $-0,047$ & 0,066 & 0,145 & 0,089 & 0,781 \\
\hline X25 & 0,307 & 0,105 & 0,698 & 0,219 & 0,097 & $-0,049$ & $-0,068$ & 0,137 & 0,053 & $-0,269$ & 0,094 & $-0,043$ & 0,101 & $\mathbf{0 , 7 7 2}$ \\
\hline X26 & 0,680 & 0,078 & 0,097 & 0,213 & 0,170 & $-0,006$ & 0,117 & 0,222 & 0,169 & 0,304 & $-0,020$ & $-0,079$ & $-0,140$ & 0,764 \\
\hline $\mathrm{X} 27$ & 0,203 & 0,250 & 0,278 & 0,099 & 0,101 & 0,007 & 0,120 & 0,141 & 0,216 & 0,262 & 0,642 & 0,311 & $-0,060$ & 0,864 \\
\hline $\mathrm{X} 28$ & $\mathbf{0 , 5 5 7}$ & 0,100 & 0,095 & 0,187 & $-0,052$ & 0,076 & 0,520 & $-0,033$ & 0,159 & 0,139 & 0,334 & 0,173 & 0,071 & $\mathbf{0 , 8 3 5}$ \\
\hline X29 & 0,707 & $-0,036$ & $-0,127$ & 0,082 & $-0,048$ & $-0,022$ & 0,242 & 0,153 & 0,058 & 0,240 & 0,416 & $-0,096$ & 0,063 & $\mathbf{0 , 7 9 9}$ \\
\hline X30 & 0,765 & 0,119 & $-0,040$ & 0,074 & 0,033 & 0,158 & $-0,067$ & 0,006 & 0,178 & 0,084 & $-0,200$ & 0,285 & $-0,000$ & 0,797 \\
\hline X31 & 0,068 & 0,462 & 0,329 & 0,340 & $-0,331$ & 0,061 & 0,329 & 0,107 & 0,089 & $-0,066$ & $-0,110$ & $-0,032$ & 0,030 & $\mathbf{0 , 7 0 2}$ \\
\hline X32 & 0,008 & $-0,056$ & 0,084 & 0,066 & 0,210 & 0,160 & 0,178 & $-0,015$ & 0,116 & 0,016 & $-0,010$ & 0,000 & 0,864 & $\mathbf{0 , 8 7 6}$ \\
\hline X33 & 0,160 & 0,173 & 0,088 & $\mathbf{0 , 8 2 2}$ & $-0,101$ & $-0,075$ & $-0,001$ & 0,046 & 0,197 & $-0,049$ & 0,078 & 0,052 & 0,128 & $\mathbf{0 , 8 2 3}$ \\
\hline
\end{tabular}


Tabela 4 - Continuação...

Table 4-Continued..

\begin{tabular}{|c|c|c|c|c|c|c|c|c|c|c|c|c|c|c|}
\hline \multirow{2}{*}{$\mathrm{V}^{1}$} & \multicolumn{13}{|c|}{ Fator } & \multirow{2}{*}{$\mathrm{CO}^{2}$} \\
\hline & 1 & 2 & 3 & 4 & 5 & 6 & 7 & 8 & 9 & 10 & 11 & 12 & 13 & \\
\hline X34 & 0,136 & 0,529 & 0,051 & 0,633 & $-0,073$ & $-0,068$ & $-0,103$ & 0,101 & 0,048 & 0,094 & $-0,290$ & 0,227 & 0,003 & $\mathbf{0 , 8 7 7}$ \\
\hline X35 & 0,271 & 0,335 & 0,166 & 0,089 & 0,499 & 0,182 & 0,106 & $-0,099$ & 0,388 & 0,149 & $-0,170$ & 0,055 & 0,244 & 0,788 \\
\hline $\mathrm{X} 36$ & 0,089 & $-0,207$ & 0,132 & $-0,135$ & 0,710 & 0,108 & 0,032 & 0,190 & $-0,338$ & $-0,196$ & 0,095 & 0,204 & 0,091 & 0,851 \\
\hline X37 & 0,004 & $-0,011$ & 0,039 & $-0,054$ & 0,867 & 0,078 & 0,102 & 0,026 & 0,097 & 0,196 & 0,017 & $-0,176$ & 0,118 & 0,867 \\
\hline X38 & 0,212 & $-0,066$ & $-0,047$ & 0,323 & 0,101 & 0,737 & 0,018 & $-0,169$ & $-0,123$ & $-0,081$ & 0,256 & $-0,091$ & 0,142 & $\mathbf{0 , 8 5 4}$ \\
\hline X39 & 0,202 & 0,179 & 0,198 & 0,690 & $-0,031$ & 0,192 & 0,361 & 0,028 & 0,119 & 0,026 & 0,118 & 0,045 & $-0,09$ & 0,796 \\
\hline $\mathrm{X} 40$ & 0,140 & 0,128 & 0,059 & 0,032 & 0,208 & 0,129 & 0,818 & 0,057 & 0,059 & $-0,001$ & 0,012 & 0,116 & 0,164 & $\mathbf{0 , 8 1 6}$ \\
\hline $\mathrm{A}^{3}$ & 12,079 & 3,396 & 2,673 & 2,610 & 1,864 & 1,816 & 1,529 & 1,341 & 1,325 & 1,046 & 0,934 & 0,918 & 0,868 & \\
\hline $\mathrm{VE}^{4}$ & 30,198 & 8,491 & 6,683 & 6,525 & 4,660 & 4,541 & 3,821 & 3,353 & 3,311 & 2,614 & 2,335 & 2,294 & 2,171 & \\
\hline $\mathrm{VA}^{5}$ & 30,198 & 38,689 & 45,371 & 51,896 & 56,555 & 61,096 & 64,917 & 68,270 & 71,581 & 74,196 & 76,530 & 78,824 & 80,996 & \\
\hline
\end{tabular}

${ }^{1}$ Variável; ${ }^{2}$ Comunalidade; ${ }^{3}$ Auto-valores; ${ }^{4}$ Variação Explicada; ${ }^{5}$ Variação Acumulada.

Observa-se a predominância de variáveis associadas aos pontos fortes (X3, X5, X6, X9) e ameaças (X32, X34, X37 e X38), seguidas de variáveis das oportunidades (X27) e (X14) das deficiências. Embora as variáveis (X3 e X9), pontos fortes pertençam ao grupo que mais influenciou na explicação dos fatores, é relevante verificar a seguir o peso significativo das variáveis (X34, X32 e X37) das ameaças.

A escolha das variáveis que compõem cada um dos treze fatores observou as cargas fatoriais de cada variável, da esquerda para a direita e ao longo de cada linha, elegendo-se (destaque em negrito) as de maior valor absoluto. Na Tabela 4, mostra-se que o Fator um, denominado "Gestão Estratégica", em razão da abrangência das variáveis, explica $30,19 \%$ das informações contidas nas variáveis selecionadas. Os maiores pesos referem-se às variáveis X1 (Acessar mercados mais seletivos), X2 (Atualização tecnológica do setor), X6 (Melhoria na gestão empresarial das empresas envolvidas), X7 (Oferecer produto diferenciado com maior valor agregado), X8 (Padrão mais elevado de qualidade, produtividade e competitividade dos produtos), X9 (Planejar de forma sustentável a atividade moveleira na região) dos pontos fortes; X18 (Baixa escolaridade dos recursos humanos que atuam no setor), X20 (Falta de qualificação da mãode-obra) das deficiências. E as variáveis X23 (Aumento da renda e densidade populacional, aumentando a demanda local e regional de mobiliário), X24 (Clima de confiança e parceria entre empresários do setor favorável à criação de um polo moveleiro), X26 (Dotar os agentes de visão estratégica capaz de lidar com a complexidade, profundidade e velocidade das mudanças), X28 (Recursos disponíveis para o setor ou área), X29 (Superara os obstáculos quanto ao porte - produção em escala/produção de móveis em série) e X30 (Valorização dos produtos do setor moveleiro) referentes a oportunidades. Os maiores pesos foram apresentados pelas X30 e X29 das oportunidades e X2 dos pontos fortes.

Na opinião de Albagli (2002), a sinergia que se estabelece na rede de empresas é considerada uma das oportunidades mais efetivas de disponibilizar capacitação, assistência técnica, superar problemas de escala, internalização de capacitação, conhecimento especializado, inteligência empresarial, logística e melhoria nas estratégias de inovação tecnológica, gerencial e de marketing para a Micro Pequena e Média Empresa (MPME).

No Fator dois, denominado "Desenvolvimento local e regional", observou-se que os maiores pesos referiam-se às variáveis X05 (Gerar emprego e renda), X10 (Promover o desenvolvimento local/regional) dos pontos fortes, X21 (Aprimoramento da logística regional), X22 (Aproveitar e aprimorar as peculiaridades locais/ regionais), e X31 (Burocracia governamental para o setor) das ameaças. Verificou-se nesse fator predominância dos quadrantes dos pontos fortes e oportunidades e não houve participação das variáveis associadas às deficiências. Esse fator explica $8,49 \%$ da variação dos dados. Os maiores pesos foram das variáveis X05 (gerar emprego e renda) e X10 (Promover o desenvolvimento local/regional) dos pontos fortes. Esse fator explica aproximadamente 8,5\% das informações contidas nas variáveis selecionadas.

Cerne, Lavras, v. 18, n. 3, p. 377-386, jul./set. 2012 
Segundo Crocco et al. (2003) e Lemos (2001), a formação de Arranjos Produtivos Locais (APLs) tem importante impacto no desempenho das empresas, especialmente nas (MPMEs) e na geração de emprego e renda, visando à elevação do nível de qualidade de vida das pessoas. Na opinião de Perafán (2007), constitui vantagem competitiva local e regional além dos recursos naturais, os atributos incorporados ao longo da história produtiva do território e a adoção de políticas de desenvolvimento que priorizem a gestão endógena do território e o "fortalecimento de um ambiente político, econômico e social", que torne a região mais atrativa que outras similares ao capital privado.

$\mathrm{O}$ terceiro Fator apresentou carregamento para três variáveis do quadrante das deficiências: X12 (Baixos investimentos em design e pesquisa de mercado), X14 (Insuficiente desenvolvimento tecnológico) e X17 (Incipiente normatização técnica aplicada à produção provocando aumento índice de desperdício, falta de padronização) e uma variável das oportunidades e X25 (Disponibilidade de matéria-prima - madeira- oriunda de reflorestamento a médio e longo prazo). Denominado de "Tecnologia e inovação", o Fator apresentou as maiores cargas para as variáveis X12 do quadrante das deficiências e X25 das oportunidades. Esse fator explica 6,68\% da variação dos dados. Quanto ao desing e desenvolvimento de novos produtos, relatório da Associação Brasileira das Indústrias do Mobiliário - ABIMÓVEL (2008) afirma que os produtos moveleiros se originam predominantemente de cópias e adaptações de revista e catálogos. A mesma associação informa que o consumidor brasileiro está valorizando mais o espaço onde mora, e a indústria está colocando à disposição móveis cada vez mais funcionais e com desing apropriado para atender a essas exigências.

O Fator quatro, denominado "Políticas Públicas", apresentou carregamento para uma deficiência X15 (Elevada informalidade) e acrescido de três ameaças: X33 (Falta de disposição política), X34 (Falta de incentivos fiscais para a área da indústria) e X39 (Políticas governamentais instáveis para o setor). O fator explica $6,52 \%$ da variação total dos dados. Segundo Caron (2004), as ameaças aos parques produtivos das MPMEs, em especial à inovação, estão no ambiente competitivo e nas variáveis da política econômica nacional de juros altos e descontinuidade dos instrumentos de apoio, cobrança na geração de emprego, não havendo em contrapartida de valorização em sua importância estratégica para o desenvolvimento nacional e local. A partir do fator quatro, o percentual de explicação das informações contidas nas variáveis é menor que 5\%, deixando de serem consideradas neste estudo.

\section{CONCLUSÕES}

Verifica-se que na opinião dos especialistas a instalação do polo é uma oportunidade de maior difusão de conhecimento e idéias, captação de recursos e valorização dos produtos do setor moveleiro. Outras contribuições estão identificadas nos pontos fortes como, geração de emprego e renda, favorecer o desenvolvimento local/regional e melhoria na gestão e competitividade dos negócios que obtiveram as médias mais elevadas. Entretanto, foram identificados gargalos como a falta de qualificação da mão de obra, baixos investimentos em desing, insuficiente desenvolvimento tecnológico, a burocracia e falta de incentivos fiscais. A sustentabilidade do polo passa pelo uso de estratégias produtivas não poluentes e recomenda-se, que o projeto seja desenvolvido de forma integrada, com as lideranças do SEBRAE, FIETO, UFT e Sindicato do segmento. É fundamental a participação do governo nesse processo, sobretudo na definição de políticas públicas voltadas para esse segmento da economia.

\section{REFERÊNCIAS}

ALBAGLI, S. Capacitação, sensibilização e informação em arranjos e sistemas de MPME. In: LASTRES, H. M. M. et al. (Ed.). Interagir para competir: promoção de arranjos produtivos e inovativos no Brasil. Brasília: SEBRAE/FINPE/ CNPq, 2002. p. 63-74.

ALMEIDA, L. T. Análise fatorial. Porto Alegre: Artmed, 1995. $97 \mathrm{p}$.

ANGELO, H.; PRADO, A. C. O desmatamento na Amazônia brasileira: FT 40 anos. Brasília: UnB, 2008. 59 p.

ASSOCIAÇÃO BRASILEIRA DAS INDÚSTRIAS DO MOBILIÁRIO. Panorama do setor moveleiro no Brasil: informações gerais. Disponível em: <http://www.abimovel. org.br/>. Acesso em: 10 maio 2008.

BARBOSA, A. P.; VIANEZ, B. F.; VEREJÃO, M. J.; ABREU, R. L. S. de. Considerações sobre o perfil tecnológico do setor madeireiro na Amazônia Central. Parcerias Estratégicas, Manaus, v. 12, p. 43-50, 2001.

BARQUERO, A. V. Desenvolvimento endógeno em tempos de globalização. Porto Alegre: UFRGS, 2002. 90 p.

Cerne, Lavras, v. 18, n. 3, p. 377-386, jul./set. 2012 
CARON, A. Inovação tecnológica em pequenas e médias empresas: estratégias e dificuldades de inovação em médias empresas industriais do Paraná. Revista FAE Busines, Curitiba, v. 8, p. 25-28, maio 2004.

CROCCO, M. A.; GALINARI, R.; SANTOS, F.; LEMOS, M. B.; SIMÕES, R. Metodologia de identificação de arranjos produtivos potenciais. Belo Horizonte: UFMG/CEDEPLAR, 2003. (Texto para Discussão, 212).

GOUVEIA, V. V.; DINIZ, P. K. C.; SANTOS, W. dos; CAVALCANTI, P. N. Metas de realização entre estudantes do ensino médio: evidências de validade fatorial e consistência interna de uma medida. Psicologia: Teoria e Pesquisa, Brasília, v. 24, n. 4, out./dez. 2008.

LEMOS, C. Inovação em arranjos e sistemas de MPME NT1.3. In: LASTRES, H. M. M. et al. (Ed.). Rede de sistemas produtivos e inovativos locais. Rio de Janeiro: UFRJ, 2001. p. 2-3.

MALHOTRA, N. K. Marketing research: an applied orientation. Englewood Cliffs: Prentice-Hall, 1993. 857 p.

MARCELINO, G. F.; FUSCALDI, K. C. Análise SWOT: o caso da Secretaria de Política Agrícola. In: CONGRESSO DA SOCIEDADE BRASILEIRA DE ECONOMIA, ADMINISTRAÇÃO E SOCIOLOGIA RURAL, 46., 2008, Rio Branco. Anais... Rio Branco: SOBER, 2008. Disponível em: <http://www.sober.org.br/palestra/9/451.pdf $>$. Acesso em: 23 abr. 2009.

MEDINA, P. Caracterização da indústria moveleira tocantinense: direito ambiental e educação ambiental. Palmas: SEBRAE-TO, 2006. 77 p.
MONTEIRO, J. H.; ZVEIBIL, V. Z. (Coord.). Manual de gerenciamento integrado de resíduos sólidos. Rio de Janeiro: UFRJ, 2001. 213 p.

OLIVEIRA, D. de P. R. Planejamento estratégico: conceitos, metodologia, práticas. 10. ed. São Paulo: Atlas, 2006. 298 p.

PAULA, J. de. Territórios, redes e desenvolvimento. In: LAGES, V.; BRAGA, C.; MORELLI, G. (Ed.). Territórios em movimento: cultura e identidade como estratégia de inserção competitiva. Brasília: Relume Dumara, 2004. p. 79106.

\section{PERAFÁN, M. E. V. O território do desenvolvimento} e o desenvolvimento do território: o novo rosto do desenvolvimento no Brasil e na Colômbia. 2007. 302 p. Tese (Doutorado em Ciências Sociais) - Universidade de Brasília, Brasília, 2007.

PORTER, M. E. Competição on competition: estratégias competitivas essenciais. Rio de Janeiro: Eliezer, 1999. 932 p.

SEIFRIED, A. Análise de ambiente. Disponível em: $<$ http://www2.ghc.com.br/GepNet/docscursos/gestao/ gestaomaterialdidatico15.pdf $>$. Acesso em: 11 abr. 2009.

\section{SERVIÇO BRASILEIRO DE APOIO A MICRO E} PEQUENAS EMPRESAS. Mercado Comum do Oeste MERCOESTE: perfil competitivo do Estado do Tocantins. Brasília, 2006. 187 p.

SILVA, J. de C. Tecnologias aplicadas à indústria moveleira. In: CICLO DE CAPACITAÇÃO TECNOLÓGICA DO SETOR MOVELEIRO, 1., 2006, Vitória. Anais... Vitória: UFES, 2006. p. 10-15.

Cerne, Lavras, v. 18, n. 3, p. 377-386, jul./set. 2012 